\title{
Monitieteistä tutkimusta mestari Franckesta
}

\author{
Hanna Pirinen
}

\section{Ulrike Nürnberger, Elina Räsänen \& Uwe}

Albrecht, toim. Meister Francke Revisited: Auf den Spuren eines Hamburger Malers. Petersberg Michael Imhof Verlag, 2017, 239 sivua.

Pohjoiseurooppalaisen keskiajan taiteen tekijyys on ajankohtaistunut uudelleen viime vuosikymmeninä tutkimusmenetelmien monipuolistuttua. Optiset ja materiaalitieteelliset menetelmät ovat syrjäyttäneet pelkkään silmämääräiseen tarkasteluun ja laajan teosaineiston tuntemukseen perustuneen attribuointiasiantuntijuuden. Monitieteisen yhteistyön tuloksena katsantokantojen vääjäämätön muutos on näkynyt jo monien pohjoiseurooppalaisten tekijänimien kohdalla. Uudelleenarvioinnin kohteena ovat jo olleet Bernt Notke ${ }^{1}$ ja Albertus Pictor ${ }^{2}$. Nyt on vuorossa mestari Francke ${ }^{3}$.

Helsingissä vuonna 2013 järjestetyn mestari Francke -seminaarin keskeistä antia on koottu
Böckler-Mare-Balticum-säätiön yhdessä maineikkaan saksalaisen taidekirjakustantajan Michael Imhofin kanssa julkaisemaan muhkeaan teokseen Meister Francke Revisited - Auf den Spuren eines Hamburger Malers, joka samalla aloittaa uuden Edition Mare Balticum -sarjan. Tyylikkäästi taitetun ja huolella kuvitetun taidehistoriallisen kirjasarjan lanseeraaminen on ihailtava kulttuuriteko aikana, jolloin akateemista maailmaa hiillostetaan nopeaan sähköiseen julkaisemiseen ja tulospisteiden tehokkaaseen hyödyntämiseen. Tätä teosta on kuitenkin suunniteltu ja toimitettu harkitusti. Työn kauniina tuloksena on julkaisu, joka laadukkuudessaan ylittää moninkertaisesti tavanomaiset pirstaleiset konferenssikirjat. Työhön vaadittu aika tekee ymmärrettäväksi sen, että osa konferenssin sellaisista papereista, joille olisi ollut luonteva paikka tässä teoksessa, on päätynyt julkaisuiksi jo aiemmin muualla. Esimerkkinä voi mainita Kersti Markuksen konferenssiesitelmänsä pohjalta muokkaaman Bar- bara-alttarin birgittalaispiirteitä analysoivan artikkelin, joka on onneksi helposti tavoitettavissa perinteikkäästä pohjoismaisesta ICO Iconografisk Post -aikakauslehdestä, joka ilmestyy nykyisin sähköisenä4.

Kirjoittajat ovat pääosin samasta tutkijapiiristä, joka oli koolla Bernt Notke -konferenssissa Tallinnassa vuonna 2009. Tuolloin ruotsalainen konservaattori-taidehistorioitsija Peter Tångeberg oli juuri jättänyt vakiintunutta Notke-kaanonia horjuttavan kirjakäsikirjoituksensa painoon. Sittemmin julkaistussa kirjassaan hän esitti, ettei Tukholman Suurkirkon Pyhä Yrjänä olisikaan Notken teos, vaan anonyymin flaamilaismestarin tuontiteos. ${ }^{5}$ Ruotsalaisprofessori Jan Svanberg on kiistänyt Tångebergin tulokset. Svanbergin kantaan voi perehtyä kirja-arvostelusta, joka on julkaistu Notke-konferenssin julkaisussa. ${ }^{6}$

Tuorein Francke-tutkimus ei tarjoile Notke-kriisin kaltaista yllätystä, joskin tekijyyskonstruktio puretaan nyt julkaistun kirjan artikkeleissa kriittisesti auki. 
Oleellisin tulos on se, että 1400-luvun alkupuolella toimineelle hampurilaismestari Franckelle attribuoidaan nykyisin vain neljä teosta. Tunnetuin näistä on Hamburger Kunsthallen osin fragmentaarisesti säilynyt Tuomas-retaabeli (Thomas Becket -retaabeli), joka on peräisin Hampurin Pyhän Johanneksen dominikaanikirkosta.

Kaksi muuta saksalaisalueella säilynyttä teosta ovat Kristusta kipujen miehenä esittäviä paneelille maalattuja hartauskuvia, joista toinen, pienempi, on kuulunut vuodesta 1858 Leipzigin Museum der bildenden Künsten kokoelmiin. Kookas, miltei luonnollisen kokoinen puolivartalokuvana esitetty Schmerzensmann oli 1890-luvulla hampurilaisessa St. Petri-kirkossa. Kummankaan Kristus-aiheisen teoksen provenienssia ei pystytä juurikaan seuraamaan.

Suomalaisille tutuin Francke-teos on Kalannin Pyhä Barbara -alttari, jonka K. K. Meinander vuonna 1908 yhdisti mestari Francken tuotantoon. Adolph Goldschmidt vahvisti attribuoinnin vuonna 1915 , joskin vasta 1921 Bella Martens ja Gustav Pauli tulivat tekemään varsinaiset havainnot paikanpäälle Suomeen. Tätä ennen Goldschmidtilla oli ollut käytössään vain mustavalkoisia valokuvia. Barbara-alttarin vahvat päällemaalaukset poistettiin perusteellisessa konservoinnissa Hamburger Kunsthallessa vuosina 1922-1925.

Ei ainoastaan Francken henkilöllisyys, vaan myös tuotanto, on kiehtonut taidehistorioitsijoita vuosikym- menestä toiseen. Ulrike Nürnbergerin, Elina Räsäsen ja Uwe Albrechtin kirjoittama konferenssikirjan johdantoartikkeli on ansiokas, ja tutkimushistorian vaiheista kiinnostunut lukija löytää siitä hyvän katsauksen myös näkökulmaistetun taidehistorian tapoihin tulkita mestari Francken kuvaston ruumiillisuutta, väkivaltaa ja henkisyyttä.

Julkaisun kirjoittajat edustavat johtavaa pohjoiseurooppalaisen keskiajan taiteen asiantuntemusta. Heillä on valmiudet laajasti vertailevaan ja suhteuttavaan teosmateriaalin tarkasteluun. Niin Francke-seminaarin kuin julkaisunkin avainhenkilöitä ovat pohjoissaksalaisen keskiajan veistostaiteen massiivisen inventointitutkimuksen vetäjä professori Uwe Albrecht ja saman hankkeen keskeinen asiantuntijajäsen tohtori Ulrike Nürnberger, molemmat Kielin yliopistosta. Kirjassa Nürnberger kirjoittaa mestari Franckelle attribuoidusta saksalaisaineistosta. Kulttuurimaantieteellinen ote ja laaja vertailuaineisto täsmentyy mm. Itämeren kulttuurialuetta käsittelevässä Gerhard Weilandin artikkelissa.

Kalannin Pyhä Barbara -alttari oli luonnollisestikin keskeinen mielenkiinnon kohde Francke-seminaarissa, ja se näkyy myös julkaisusta, jossa teoksesta kirjoittavat Markus Hiekkanen ja Elina Räsänen. Barbara-retaabeliin kuvattujen hahmojen liikkeitä, asentoja ja keskinäistä vuorovaikutusta Räsänen tarkastelee vielä omassa erillisessä artikkelissaan. Tarton yliopiston keskiaikaisen veistotaiteen ekspertti

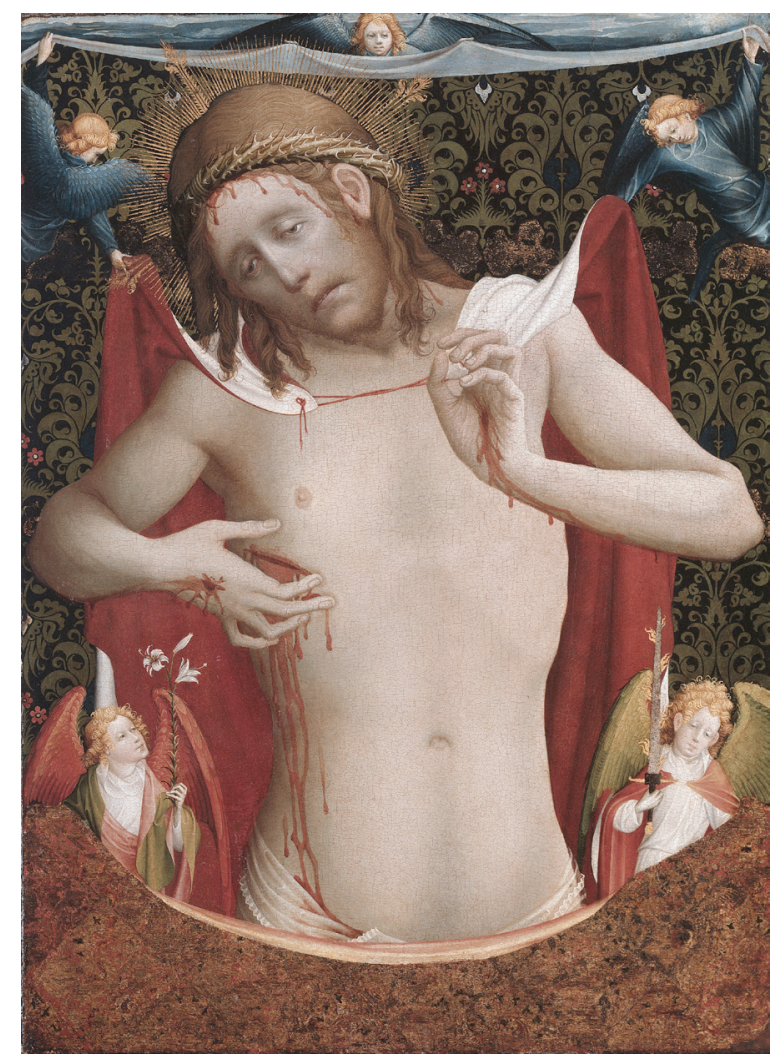

Kuva 1. Mestari Franckelle attribuoidaan kaksi Kristusta kipujen miehenä esittävää temperalla paneelille maalattua teosta. Niistä kookkaampi $(92,5$ x $67 \mathrm{~cm})$ kuuluu Hamburger Kunsthallen kokoelmiin. Se ajoitetaan 1430-luvulle. Tempera puupannoolle, 92,5 x $67 \mathrm{~cm}$. Hamburger Kunsthalle. https://commons. wikimedia.org/wiki/File:Vir Dolorum, by Master_Francke.jpgVir_Dolorum, by Master Francke.jpg 
Krista Andreson on keskittynyt suuren alttarikaapin Maria-sykliin ja yhteyksiin lyypekkiläisveistoon. Uwe Albrecht puolestaan on perehtynyt Barbara-alttarin kehystykseen laajan vertailuaineistonsa avulla.

Teknologisen tutkimuksen tuloksia kaikkien neljän mestari Franckelle attribuoitavan teoksen osalta kuvaa Silvia Castro, joka on hampurilainen tekninen taidehistorioitsija ja konservaattori. Castron artikkelissa laajimman tarkastelun saa Hampurin Tuomas-alttari. Silvia Castron koordinoiman materiaalianalyyttisen osion tulokset ovat syntyneet tiimityönä, johon ovat osallistuneet monet saksalaisten tutkimuslaitokset. Tässä Franckeen keskittyvässä yhteistyössä on käytetty materiaalitieteellisistä menetelmistä röntgenfluoresenssispektroskopiaa, dendrokronologista tutkimusta, perinteistä röntgentutkimusta ja infrapunareflektografiaa. Työssä käytettiin niin teokseen kajoamattomia kuin näytteenottoonkin perustuvia menetelmiä, joten materiaaleista, kuten puusta, pigmentti- ja sidosaineista sekä lehtimetalleista saatiin syvällistä tietoa. Kiinnostavan lisän kokonaisuuteen tuo Pyhä Barbara -alttarin konservointihistorian vaiheita 1920-luvulta alkaen tarkasteleva konservaattori Henni Reijosen artikkeli.

Materiaalitieteellisen tutkimuksen tulokset merkitsevät tärkeää virstanpylvästä keskiajan taiteen tutkimuksessa. Francke-tutkimuksen historiallisesti kontekstoivassa osuudessa vastaavalla tavalla
Kuva 2. Elina Räsänen keskittyy artikkelissaan Kalannin Pyhä Barbara-retaabelin hahmojen liikkeisiin ja asentoihin. Kädet osoittautuvat paljon puhuviksi kertomuksen eri vaiheissa. Ensimmäisessä paneelissa pakanaisä Dioskuros väittelee kauniin tyttärensä Barbaran kanssa kolmen torni-ikkunan merkityksestä. Viimeisimmän tutkimuksen mukaan mestari Francken Barbara-alttari valmistui vuoden 1421 jälkeen, todennäköisesti 1430-1440-luvulla. Munatempera liitupohjustukselle, $91 \times 54 \mathrm{~cm}$ Kuva: Riitta Pylkkänen / Suomen kansallismuseo. https://commons. wikimedia.org/wiki/ Category:Meister Francke?uselang =de\#/media/File:Pyh\% $3 \%$. 34 n Barbaran alttarikaappi 1.jpg
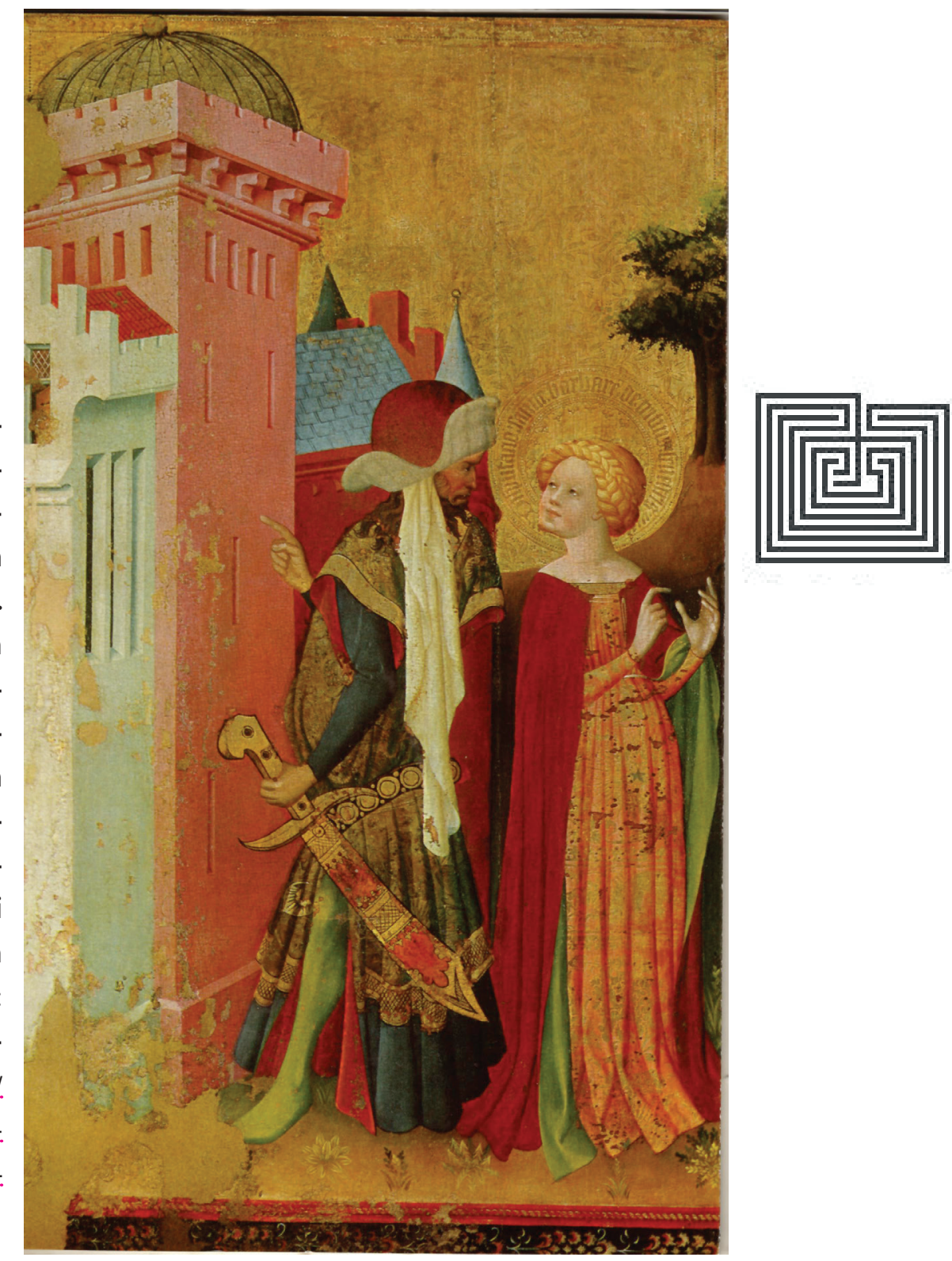
uutta tutkimuslinjaa avaavat ikonografisten tyyppien leviämisestä tehdyt tuoreet havainnot. Samanaikaista, joskaan ei Franckelle attribuoitavaa, Osnabrückin kiviretaabelia käsittelevä Reinhard Karrenbrockin artikkeli nostaa esiin birgittalaisuuden roolin, jota Kersti Markus ${ }^{7}$ on jo aiemmin korostanut Pyhä Barbara -alttarin tulkinnassa. Luoteissaksalaisella alueella säilyneessä kiviretaabelissa näkyy birgittalaisuuden vaikutus, mikä kuvastaa keskiajan veistäjien notkeutta omaksua uusia täsmällisiin näkyihin ja ilmestyksiin perustuvia kuvaamistapoja. Alueelliset etäisyydet voittavasta viestintätehosta kertoo se, että mallit ja esikuvat kulkeutuivat nopeasti verstaalta toiselle läntisen universaalikirkon hallitsemalla kulttuurialueella. Samanlaiset aiheet ja esitystavat eivät merkitse samaa tekijää, vaan yhteisten ja laajasti omaksuttujen mallien vaikutusta. Asiakirjojen kautta dateerattavissa tapauksissa, kuten Hampurin Tuomas-alttarissa tulee näkyviin ensimmäisenä birgittalainen vaikutus alasaksalaisella alueella.

\section{Mestari Francke taidehistoriallisena konstruktiona} Mestari Francken taidehistoriallinen tarina oli käynnistynyt vuonna 1899 Hampurin kaupunginarkiston tutkija Anton Hagedornin julkaistua otteita hampurilaisten Englannin-kauppaa tehneiden kauppiaiden killan memoriaalikirjasta vuodelta 1541. Mitä ilmeisimmin 1500-luvun kirjuri on kopioinut joulukuuhun
1424 ajoittuvan sopimustekstin väärin. Asia koski dominikaanien Pyhän Johanneksen kirkossa sijainneen kiltakappelin alttariteosta. Alkuperäistä lähdettä ei ole sittemmin tavoitettu, mutta merkinnässä on ollut riittävästi aineksia taidehistorialliselle mielikuvitukselle, jotta voitiin muodostaa näkemys, jonka mukaan Tuomas-alttarin tekijä oli mestari Francke ja teoksen valmistumisvuosi 1424. Myöhemmät tutkijat ovat lähdekriittisessä mielessä kyseenalaistaneet suppeasta lähdemerkinnästä vedetyt johtopäätökset. Ensinnäkin transkriptio on todennäköisesti virheellinen, eikä tekstissä toisaalta mitenkään yksilöidä mestari Francken roolia. Hän ei ehkä ollut maalari-veistäjä, kuten oletetaan, vaan mahdollisesti eräänlaisessa urakoitsijan roolissa toiminut puuseppä, joka vastasi kaapin rakenteen puutyöstä.

Lähdemerkinnän julkaisuaikana 1800-luvun loppupuolella Itämeren vauraat rantakaupungit vaalivat ylpeästi alueellista omaleimaisuuttaan. Paikallispatriotismille oli tärkeää pystyä osoittamaan hampurilaismestareita lyypekkiläisdominanssin rinnalle. Näin siis mestari Francke ja hänen tuotantonsa mieluusti vakiinnutettiin historialliseksi hampurilaistotuudeksi perusteita sen tarkemmin kaivelematta. Saksalaistaidehistorioitsijat pitäytyivät Carl Georg Heisen julkaisemaan pohjoissaksalaisen maalaustaiteen historiaan (1918) asti perustaltaan yhtenäisessä näkemyksessä, joskin Heise patriotismin puristamista ahtaahkoista rajoista huolimatta rohkeni luonnehtia maalaria kansainväliseksi ja eurooppalaisen tyylin omaksuneeksi. Hän pyristeli näin irti yhtenäisen hampurilaistyylin kehyksestä.

Standarditeokseksi Francke-tutkimuksessa muodostui Bella Martensin väitöskirja vuodelta 1929. Osin pulmallinen tulkinta piti yhtenä ja samana henkilönä hampurilaislähteiden Franckea ja alankomaalaista dominikaanimunkki Franckea, joka oli kotoisin Zutphenista.

Stephan Kamperdick erittelee artikkelissaan kriittisesti Francke-attribuution vaiheet ja ampuu alas tekijyyskonstruktion rakennepalikat. Francke ei voinut olla dominikaaniveli. Hän ei ollut tulokas, vaan pohjoissaksalainen. Nimikään ei todennäköisesti ollut Francke, vaan ehkä kiekuraisella keskiajan saksalaisella kaunokirjoituksella raapustettu Hans tai oikeastaan pikku-Hans (Hansshen). Kamperdick ei kuitenkaan jätä mysteeriä avoimeksi, vaan jatkaa vertaillen ja kriittisellä suhteuttamisella potentiaalisen tekijän etsintää. Hans, joka voisi olla sopimustekstin mainitsema tekijä, saattaa olla Hans (Henselin) strassburgilainen, joka ikämiehenä ehkä jätti työn kyvykkäimmille apulaisilleen. Todennäköisimmältä aikahaarukkaan sopivalta vaikuttaa Conrad von Vechta (tai Cord van der Vechte), joka vaikutti säilyneiden lähteiden perusteella 1420-luvulta kuolemaansa vuoteen 1448 asti Hampurissa. Toinen mahdollinen henkilö oli Hans Bornemann, Conrad von Vechtan ykkösapulainen, joka sai mestarinoikeudet 
vuonna 1445 ja jatkoi oppi-isänsä verstastaan toimintaa tämän kuoleman jälkeen.

\section{Kalannin Pyhä Barbara -alttari}

Suomalaislukijaa kiinnostaa arvatenkin erityisesti Kalannin Barbara-alttaria koskeva tuorein tutkimustieto. Markus Hiekkanen ja Elina Räsänen tiivistävät artikkelissaan keskeiset pulmakohdat ja käyvät ne loogisesti perustellen läpi alkaen kookkaan teoksen ajoitushypoteeseista, hankinnasta ja alkuperäisestä sijoituspaikasta. He osoittavat pitämättömäksi Juhani Rinteen oletuksen teoksen hankinnasta Turun tuomiokirkkoon, josta se olisi myöhemmin siirretty Kalantiin.

Teos on valmistettu tilauksesta vuoden 1421 jälkeen, todennäköisimmin 1430- tai 1440-luvulla ehkä osana laajempaa kirkon rakentamisen ja varustamisen kokonaissuunnitelmaa. Dateerauksen varmentavat hampurilaisen professori Peter Kleinin vuonna 1996 tekemät dendrokronologiset tutkimukset.

Toisin kuin joissakin teksteissä annetaan ymmärtää, Kalannin kirkko ei ole vaatimaton kyläkirkko, vaan se on sijainniltaan Turusta katsottuna keskeisen lounassuomalaisen kulttuurireitin varrelle sijoittuva tärkeä kirkkorakennus. Pitäjä oli sivistyksellisesti vaurasta rintamaata, mikä kuvastuu kirkon seinille kalkkimaalein maalatuista vaakunoista, jotka kuuluvat merkittäville kirkonmiehille ja rälssisuvuille.
Suuri alttarikaappi on hankittu ajan merkittävimpien kaupallisten ja kulttuuristen verkostojen kautta Itämeren eteläpuolelta hyödyntäen Turun piispan Maunu Tavastin kaltaisten vauraiden johtomiesten apua Paikallisyhteisölle tällainen monista visuaalisista ja hengellisistä kerrostumista koostuva teos olisi ollut liian haasteellinen. Kuvaohjelman laadinta ja tilauksen järjestelyt ovat edellyttäneet erityisasiantuntemusta. Teoksen mitat ja kirkon kuoriseinän mitat osoittavat, että alttarikaappi on sopinut hyvin paikalleen pääalttarin äärelle. Retaabeli oli paikoillaan aina 1800-luvulle asti, joskin päällemaalausten osin muuttamana.

\section{Itämeren-piirin keskiajan taiteen tutkimuksellinen päivitys}

Francke-tulosten ja aikaisempien Notke ja Albertus -julkaisujen jälkeen Itämeren-piirin keskiajan taideilmiöiden uudelleenarviointi vaikuttaa saavuttaneen suvantovaiheen, jossa kaksi tutkimuslinjaa sivuavat toisiaan. Ensinnäkin systemaattinen, uusia tekniikoita soveltava ja monitieteisesti työskentelevä teosperusteinen tutkimus osoittaa evidenssiarvonsa. Toisaalta Franckeen keskittyvä tutkimushistoriallinen katsaus osoittaa, että mestarin teokset ovat ehtineet kohdata monenlaista luentaa. Teokset ovat inspiroineet myös tutkimuksellisten käsitteiden kautta operoivaa ja näkökulmaistettua taidehistoriaa. Näiden tutkimusasenteiden ero tulee esiin suhtautumisessa historiallisen kontekstoinnin rooliin ja merkitykseen.
Visuaalisen kulttuurin teoskäsitys pyrki irtaannuttamaan taidehistorioitsijat historiallisesta kontekstoinnista 30 vuotta sitten. Normanbrysoninsa ja miekebalinsa huolella lukeneet vanhemman polven taidehistorioitsijat muistavat, että kärkevimmilleen tiivistettynä Bryson ja Bal tiukan linjan visualistiteoreetikkojen kärkiniminä katsoivat historiallisen kontekstoinnin tekevän väkivaltaa teokselle visuaalisena representaationa. Heidän näkemyksensä mukaan teoksia voitiin tulkita kulttuurisina teksteinä ilman että lähdetyöskentelyllä niihin kuorrutettiin petollista narratiivia tai ne alistettiin dokumentiksi. ${ }^{8}$ Murrosvaiheen poleemisista teksteistä voitaneen nostaa esiin kuitenkin arvonsa säilyttävänä oppina kriittinen asenne tulkinnan taustakehikoiden rakentelua kohtaan.

Pohjoiseurooppalaiseen keskiajan taiteeseen kohdennettuna tutkijan sudenkuopiksi saattavat käsitteellisimmissä rajauksissa paljastua lähdepulmat tai asioiden suhteellisuudesta johtuvat seikat. Todellisuudessa reunaehdot voivat poiketa huomattavasti hegemonisten rakenteiden yleislinjauksista. Näin on käynyt esimerkiksi nyttemmin virheelliseksi näyttäytyvälle oletukselle mestari Franckesta dominikaaniveljenä. Visuaalisessa luennassa painotettu dominikaaniaspekti onkin syrjäytynyt, kun on voitu osoittaa birgittalaiskuvaston aiempaa oletusta laajemmalle ja oletettua varhaisemmin levinnyt suosio. On syytä muistaa, ettei edes keskiajan katolinen kirkko toiminut univer- 
saaliluonteestaan huolimatta kaikkialla täysin sa-

moin. Sävyerot johtuvat esimerkiksi siitä, että monet sääntökunnat hallitsivat varsin rajattuja alueita, joskin jonkin tietyn järjestön vaikutus saattoi levitä nopeasti tai vain rajattuun ilmiöön, kuten kuvataiteeseen. Tästä käy hyväksi esimerkiksi mestari Francke-tutkimuksen tulos birgittalaisen kuvamaailman suhteen.

Kaikkineen mestari Francken jalanjäljillä olleet tutkijat ovat saaneet kokoon kantavia ja pohdittuja tuloksia, jotka osoittavat tällaisen päivityksen tarpeellisuuden. Esineenä kaunis ja sisällöltään painava teos piirtää lukijalleen hyvän kuvan itämerellisen taidehistorian nykyisistä tavoista lähestyä tekijyyttä monitasoisena kysymyksenä. Kirjaa voi suositella kaikille pohjoiseurooppalaisesta keskiajan taiteesta kiinnostuneille ajankohtaisena esimerkkinä monititieteisen kohtaamisen mahdollisuuksista.

\section{Viitteet}

1 Art, cult and patronage. Die visuelle Kultur im Ostseeraum zur Zeit Bernt Notkes. Toim. Anu Mänd \& Uwe Al-brecht. Kiel: Verlag Ludwig, 2013.

2 Albertus Pictor. Målare av sin tid 1. Bilder i urval samt studier och analyser. Toim. Pia Melin. Stockholm: Kungl. Vitterhets historie och antikvitets akademien, 2009; Sandquist Öberg \& Christina, Albertus Pictor. Målare av sin tid 2. Samtliga bevarade motiv och språkband med kommentarer och analyser. Stockholm: Kungl. Vitterhets historie och antikvitets akademien, 2009; kirja-arvostelu Pirinen, Hanna, "Systemaattista tutkimusta ruotsalaisen keskiajan taiteen mestarista. Albertus Pictor -juhlavuoden satoa", Tahiti 1/2013 Luettu 30.1.2018, http://tahiti.fi/01-2013/kirja-arvostelut/.

3 Taustatukea tutkimuksen tulosten julkaisemiselle on tullut mm. saksalaiselta Böckler-Mare-Balticum -säätiöltä, joka on osallistunut keskeisesti Notke ja Francke -symposiumien järjestämiseen sekä vuosien ajan ylläpitänyt Homburger Gespräche -nimistä symposiumien sarjaa. Säätiö on tukenut muutenkin monin tavoin Baltian maihin ja Itämeren alueeseen liittyvää taidehistoriallista tutkimusta.

4 Markus, Kersti, "The Saint Barbara Altarpiece of Master Francke and its Birgittine Context", ICO Iconographisk Post. Nordisk tidskrift för bildtolkning - Nordic Review of Iconography nro 4 (2014): 4-24. Luettu 30.1.2018. https://ojs.abo.fi/ojs/index.php/ico/ article/view/894

5 Tångeberg, Peter, Wahrheit und Mythos. Bernt Notke und die Stockholmer St.-Georgs-Gruppe. Studien zu einem Hauptwerk niederländischer Bildschnitzerei. Ostfildern: Thorbecke, 2009; kirjaarvostelu Pirinen, Hanna, "Myyttinen Bernt Notke", Tahiti nro 1/2011. Luettu 30.1.2018. http://tahiti.fi/012011/kirja-arvostelut/myyttinen-bernt-notkel. 6 Svanberg, Jan, "Was the St George group in
Stockholm made in Antwerp by an unknown Flemish master?" Art, cult and patronage, 323-329.

7 Ks. viite 4

8 Bryson, Norman, "Introduction". Calligram: Essays in New Art History from France. Cambridge: Cambridge University Press 1988, xxvviii-xxix; esimerkkinä visuaalisesta luennasta Bal, Mieke, Reading Rembrandt: Beyond the word-image opposition. Cambridge: Cambridge University Press, 1988, myös toinen editio Amsterdam: Amsterdam University Press, 2006; Pirinen, Hanna, "Biografinen ja historiallinen näkökulma taiteen-tutkimukseen”. Taidetta tutkimaan. Menetelmiä ja näkökulmia. Toim. Annika Waenerberg \& Satu Kähkönen. Jyväskylä: Kampus Kustannus, 2012, 281, 292-293.

Dosentti Hanna Pirinen työskentelee yliopistotutkijana Jyväskylän yliopistossa. Hän on tutkinut erityisesti 1500 - ja 1600-luvun taiteen ilmiöitä. Viime vuosina hän on myös edistänyt taidehistoriallisen, materiaalitieteellisen ja optisia menetelmiä soveltavan tutkimuksen kaupallistamista monitieteisessä taideteostutkimushankkeessa, josta on syntynyt tutkimustoimintaa harjoittava yritys. 